\title{
Sciendo
}

\section{Preface: Philosophical Basis for Making Decisions (on the 140th Anniversary of the Birth of Jan Lukasiewicz)}

\author{
Jan Woleński \\ University of Information Technology \\ and Management in Rzeszow, \\ Sucharskiego 2 Street, \\ 35-225 Rzeszow, Poland \\ e-mail: jan.wolenski@uj.edu.pl
}

\author{
Andrew Schumann \\ University of Information Technology \\ and Management in Rzeszow, \\ Sucharskiego 2 Street, \\ 35-225 Rzeszow, Poland \\ e-mail: andrew.schumann@gmail.com
}

\begin{abstract}
:
It is a Preface to Volume 8:2 (2019) consisting of articles presented at the International Interdisciplinary Conference anniversary of the birth of Jan Łukasiewicz, Rzeszów, Poland.

Keywords: Łukasiewicz, many-valued logic, non-classical logic, Lviv-Warsaw School of Logic, Lvov-Warsaw School of Logic.
\end{abstract}

The International Interdisciplinary Conference Philosophical Basis for Making Decisions and NonClassical Logics has been organized by dr. Andrew Schumann, dr. Włodzimierz Zięba, dr. Paweł Balcerak, dr. Konrad Szocik on the 140th anniversary of the birth of Professor Jan Łukasiewicz (born on December, 21st 1878 in Lviv (Polish: Lwów), a city in today's Ukraine, and died on February, 13th 1956), who was a famous representative of Lviv-Warsaw School of Logic with contributions to philosophical logic, mathematical logic, and history of logic. Using some philosophical ideas of Aristotle's De Interpretatione (ch. IX) (namely, his asserting that the application of the law of excluded middle to future propositions like, 'There will be a sea-battle tomorrow' should be categorically restricted), Jan Łukasiewicz proposed the first version of manyvalued logic (1920). So, he showed that even some features of real world which are out of classical logic such as dynamics can be described and modeled logically still by non-classical systems. This finding that logic and rationality can be detected even in non-logical processes is quite typical for the Lviv-Warsaw School of Logic and distinguishes this school from the Vienna Circle (German: 
Wiener Kreis) focusing only on classical logic and their natural extensions. Hence, the motto of this conference was that rationality can be observed everywhere. Over the past two decades our social world has changed a lot due to new media. One of the biggest changes is communications in social networks which became an important part of our everyday's life. But new forms of social communication are out of traditional forms of logical analysis of discourse. For instance, in these media the standard referential conception of truth is inapplicable - we cannot check uttered facts, but we can check contexts of uttering. In this way, we are interested to discuss non-classical logics in decision making and cognitions, new forms of communication and decision making, communication in new media.

Volume 8:2 (2019) of Studia Humana is a Postproceeding of the Conference described above. In this volume, the papers are devoted to different aspects of rationality. So, the paper Logical Ideas of Jan Łukasiewicz written by Jan Woleński discusses some logical ideas put forward by Jan Łukasiewicz within their historical context and development. The paper Logical Determinacy versus Logical Contingency. The Case of Łukasiewicz’s Three-valued Logic submitted by Andrew Schumann is concentrated on explicating a logical intuition of Jan Lukasiewicz provided him to the idea of many-valued logic. The paper Dispute over Logistic between Jan Łukasiewicz and Augustyn Jakubisiak. Why was it important? written by Bartłomiej K. Krzych is devoted to the polemics with Lukasiewicz initiated by Augustyn Jakubisiak who criticized Łukasiewicz's logistics for its anti-metaphysical and anti-theological role. In the paper The Analogy in Decision-Making and the Implicit Association Bias Effect its author, Nataliia Reva, considers the thinking by analogy as a natural instrument human have because of the mirror neurons in our brain. The contribution About Possible Benefits From Irrational Thinking in Everyday Life written by Magdalena Michalik-Jeżowska is focused on indicating some benefits that may become a result of irrational thinking in the everyday human practice. The given examples of irrational thinking come from research in the field of cognitive and social psychology and behavioural economics. Magdalena Hoły-Łuczaj in her paper Moral Considerability and Decision-Making analyses "affectability" as a capacity of an agent to affect a considered entity. Such an approach results in significant changes in the scope of moral considerability and is relevant for discussing the human position in the Anthropocene. The paper Practical Rationality - its Nature and Operation prepared by Andrzej Niemczuk presents a proposal of explanation what practical rationality is, how it works and what are its criteria. Paweł Balcerak in his contribution Can the Sense of Agency Be a Marker of Free Will? analyses the relation between agency and responsibility. Finally, the paper On Computers and Men written by Tomasz Goban-Klas is addressed to the question how information technologies have transformed our thought on two levels: self-conception and relation to nature. 